\title{
Symptomatic late-onset hypogonadism but normal total testosterone: the importance of testosterone annual decrease velocity
}

\author{
Sandro La Vignera ${ }^{1}$, Rosita A. Condorelli ${ }^{1}$, Aldo E. Calogero ${ }^{1}$, Rossella Cannarella ${ }^{1}$, Laura M. Mongioì ${ }^{1}$, \\ Ylenia Duca ${ }^{1}$, Laura Cimino ${ }^{1}$, Filippo Giacone ${ }^{1}$, Antonio Aversa ${ }^{2}$ \\ ${ }^{1}$ Department of Clinical and Experimental Medicine, University of Catania, Catania, Italy; ${ }^{2}$ Department of Experimental and Clinical Medicine, \\ University Magna Graecia of Catanzaro, Catanzaro, Italy \\ Correspondence to: Prof. Sandro La Vignera. Department of Clinical and Experimental Medicine, University of Catania, via S. Sofia 78, 95123 Catania, \\ Italy. Email: sandrolavignera@unict.it. \\ Provenance and Peer Review: This article was commissioned by the editorial office, Annals of Translational Medicine. This article did not undergo \\ external peer review.
}

Submitted Jul 08, 2019. Accepted for publication Sep 11, 2019.

doi: $10.21037 / \mathrm{atm} .2019 .11 .48$

View this article at: http://dx.doi.org/10.21037/atm.2019.11.48

Late-onset hypogonadism (LOH) is a relevant condition from an epidemiological perspective, since it has an estimated prevalence of $2.1 \%$ (1). In recent years, this issue has gathered growing interest, due to the possible adverse effects which testosterone replacement therapy (TRT) may expose to. Notably, $\mathrm{LOH}$ arises in aging, a period of life wherein cardio-metabolic diseases are highly prevalent (2) and the risk for cardio- and cerebro-vascular events is not negligible (3).

LOH seems to be due to a central (hypothalamic-pituitary) or testicular dysfunction, which may concomitantly occur in some cases. This editorial aims to discuss the management of patients with symptomatic $\mathrm{LOH}$ but with total testosterone (TT) levels in the lowest quartile of the normal range.

Before deepening into the pharmacological issue, some premises have to be made.

First of all, prior to make $\mathrm{LOH}$ diagnosis, a proper evaluation of the clinical conditions leading to $\mathrm{LOH}$-like symptoms (e.g., anemia, hypothyroidism, hypocortisolism, mood disorders) should be accomplished, although sexual dysfunctions (erectile dysfunction, decreased libido) show a high specificity for LOH (4). Accordingly, the European Male Aging Study (a cohort study of community-dwelling middle-aged and older men in Europe) found that only sexual symptoms (poor morning erections, decreased libido, and erectile dysfunction) are associated with TT and free-testosterone (FT) concentrations (5). In addition, validated questionnaires might represent a potentially useful diagnostic tool for differential diagnosis (6), despite their use is not fully recognized by the current guidelines (7).

Second, TT serum measurement is usually done by chemiluminescence immunoassay (CLIA) in the clinical practice, although radioimmunoassay (RIA) or liquid chromatography-tandem mass spectrometry (LC-MS/MS) are the only two assays mentioned by the Endocrine Society (ES) guidelines. Specifically, the last ES guidelines define LC-MS/MS as the assay offering the highest specificity, sensitivity and precision for TT (especially in the low range) than do most immunoassays (7). Currently, the diagnosis of $\mathrm{LOH}$ is made for TT serum levels lower than $264 \mathrm{ng} / \mathrm{dL}$ $(9.2 \mathrm{nmol} / \mathrm{L})$. To confirm the diagnosis, at least two $\mathrm{T}$ measurements are needed (7). FT measurement should be performed by the equilibrium dialysis method or calculated if this method is not available in men whose serum TT concentration is around the lower limit (e.g., 200 to $400 \mathrm{ng} / \mathrm{dL}$ ) of normal range (7).

Actually, the concept of "Testosterone Annual Decrease Velocity" is not considered, despite data from 
the Massachussets Male Aging Study (MMAS) showed a testosterone annual decrease in the adulthood of $1.6 \%$ per year of age (8). Testosterone decrease begins when bone mass peak occurs. It is highly heterogeneous, especially in case of metabolic (e.g., obesity) or chronic diseases, that associate with a higher annual decrement rate. $T$ decrease may hypothetically be responsible for symptoms based on the degree of the intra individual annual variation. Therefore, TT measurement starting from the adulthood would be of great utility to assess whether a greater than expected decline occurs in aging.

Few markers of Leydig cell dysfunction, which may anticipate TT decline have been proposed. In particular, insulin-like 3 (INSL-3), a Leydig cell-derived glycoproteic hormone, may represent a good candidate. Similarly, the rise of luteinizing hormone $(\mathrm{LH})$ in the presence of normal serum TT identify a "subclinical hypogonadism" (9), whose treatment is not codified by none of the current available guideline. Alteration of testicular function occurring in aging may also be assessed by non-hormonal methods, such as ultrasound scan, which can usefully detect testicular volume decrease or changes into echo texture, due to a progressive rarefaction of the testicular parenchyma compared to that of the fertile age.

Some polymorphisms in the androgen receptor (AR) are known to influence the AR responsiveness to testosterone, affecting signal transduction intensity. Particularly, the number of CAG trinucleotide repeats is one of the most studied. A low number of repeats is associated with a higher AR activity, thus raising the risk for prostate cancer (10). This polymorphism is not taken into account in the clinical practice.

Moreover, some features may resemble $\mathrm{LOH}$, such as (I) lower prostate volume (evaluated by ultrasound) in comparison with aged-matched peers or low total PSA levels, an index of prostate volume and androgenization (11), (II) apparently idiopathic low hematocrit levels, suggested by the role of TT on erythropoiesis (TRT is contraindicated in case of pre-treatment hematocrit levels of $48 \%$ or when it is $>54 \%$ during TRT) (12).

Finally, patients with apparently idiopathic primary osteoporosis (secondary forms, e.g., those due to hyperparathyroidism, hypercortisolism, etc. have to be excluded) and hypovitaminosis D should also be checked for
LOH. In particular, hypovitaminosis D may hide a central hypogonadism, due to the LH-induced hydroxylation of vitamin $\mathrm{D}$ at the testicular level (13).

On the basis of the above-reported considerations, would it be reasonable to consider TRT in the following cases characterized by TT levels within the lowest quartile of the normal range?

(I) Hypogonadism-related symptoms and Testosterone Annual Decrease Velocity higher than expected;

(II) Hypogonadism-related symptoms, decreased testicular volume and echo tessiture rarefaction;

(III) Hypogonadism-related symptoms and low INSL-3 levels;

(IV) Hypogonadism-related symptoms and high number of CAG trinucleotide repeat of the AR;

(V) Hypogonadism-related symptoms, low prostate volume and/or low PSA values compared to agedmatched peers;

(VI) Hypogonadism-related symptoms and (idiopathic) low hematocrit values;

(VII) Hypogonadism-related symptoms and idiopathic primary osteoporosis.

In all of these combinations, the exclusion of previously mentioned diseases causing LOH-like symptoms has to be carefully accomplished prior to plan TRT.

An experimental proposal may be to start TRT using half dose of that usually used for hypogonadism. Any possible side effect has to be timely detected adopting a shorter follow-up, which may be done after 6, 12 and 24 weeks [or 3, 6 (or 9 according to the clinician's judgement) and 12 months and at least annually thereafter as currently suggested for hypogonadal patients in TRT by the current guidelines (14)]. In addition, transdermal preparations could be preferred to injective ones when a low dosage is required. Furthermore, the interruption of the administration of this latter preparation more rapidly allows a decrease of serum testosterone concentrations compared to the injective one. The improvement of symptoms after the beginning of TRT would confirm LOH diagnosis. Conversely, if no benefits ensue, TRT should be suspended.

Finally, to overcome the pitfalls of the current clinical practice, TT measurement from the age of 20 should be done (for example, every 5-10 years) in all men to assess testosterone annual decrease velocity (Figure 1). 


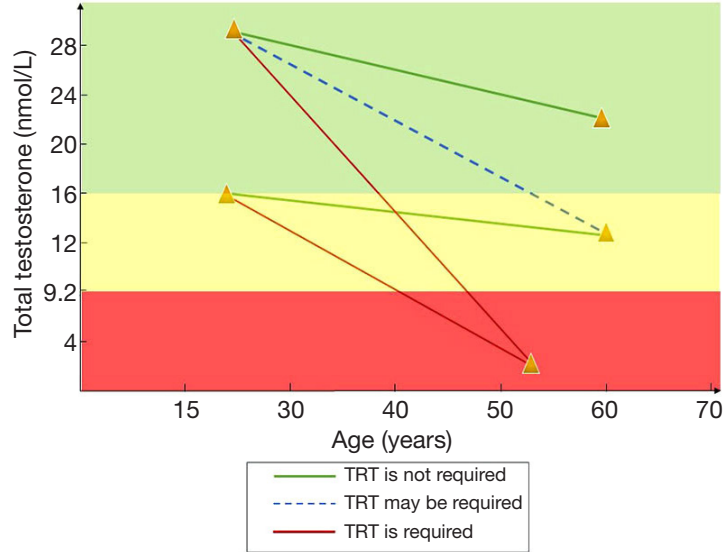

Figure 1 Schemes of testosterone replacement therapy (TRT) according to testosterone annual decrease velocity. TRT is currently administered when total testosterone (TT) serum levels are lower than $9.2 \mathrm{nmol} / \mathrm{L}$. However, values in the lowest quartile of the normal range $(9.2-16 \mathrm{nmol} / \mathrm{L})$ may require TRT in symptomatic patients having higher than the expected testosterone annual decrease velocity. Red: serum TT range requiring TRT; Yellow: serum TT range which may require TRT in symptomatic patients having higher than the expected testosterone annual decrease velocity; Green: serum TT range not requiring TRT.

\section{Acknowledgments}

Funding: None.

\section{Footnote}

Conflicts of Interest: SLV as an unpaid editorial board member of ATM from Nov 2019 to Oct 2021. The other authors have no conflicts of interest to declare.

Ethical Statement: The authors are accountable for all aspects of the work in ensuring that questions related to the accuracy or integrity of any part of the work are appropriately investigated and resolved.

Open Access Statement: This is an Open Access article distributed in accordance with the Creative Commons Attribution-NonCommercial-NoDerivs 4.0 International License (CC BY-NC-ND 4.0), which permits the noncommercial replication and distribution of the article with the strict proviso that no changes or edits are made and the original work is properly cited (including links to both the formal publication through the relevant DOI and the license). See: https://creativecommons.org/licenses/by-nc-nd/4.0/.

\section{References}

1. Tajar A, Huhtaniemi IT, O'Neill TW, et al; EMAS, Group. Characteristics of androgen deficiency in late-onset hypogonadism: results from the European Male Aging Study (EMAS). J Clin Endocrinol Metab 2012;97:1508-16.

2. La Vignera S, Calogero AE, Condorelli R, et al. Andrological characterization of the patient with diabetes mellitus. Minerva Endocrinol 2009;34:1-9.

3. La Vignera S, Calogero AE, D'Agata R, et al. Testosterone therapy improves the clinical response to conventional treatment for male patients with metabolic syndrome associated to late onset hypogonadism. Minerva Endocrinol 2008;33:159-67.

4. Tharakan T, Miah S, Jayasena C, et al. Investigating the basis of sexual dysfunction during late-onset hypogonadism. F1000Res 2019. doi: http://dx.doi. org/10.12688/f1000research.16561.1.

5. Wu FC, Tajar A, Beynon JM, et al; EMAS Group. Identification of late-onset hypogonadisminmiddle-aged and elderlymen. N Engl J Med 2010;363:123-35.

6. Neijenhuijs KI, Holtmaat K, Aaronson, NK, et al. The International Index of Erectile Function (IIEF)-A Systematic Review of Measurement Properties. J Sex Med 2019;16:1078-91.

7. Bhasin S, Brito JP, Cunningham GR, et al. Testosterone Therapy in Men With Hypogonadism: An Endocrine Society Clinical Practice Guideline. J Clin Endocrinol Metab 2018;103:1715-44.

8. Feldman HA, Longscope C, Derby CA, et al. Age trends in the level of serum testosterone and other hormones in middle-aged men: longitudinal results from the Massachusets Male aging Study. J Clin Endocrinol Metab 2002;87:589-98.

9. Foresta C, Calogero AE, Lombardo F, et al. Late-onset hypogonadism: beyond testosterone. Asian J Androl 2015;17:236-8.

10. Tan MH, Li J, Xu HE, et al. Androgen receptor: structure, role in prostate cancer and drug discovery. Acta Pharmacol Sin 2015;36:3-23.

11. La Vignera S, Condorelli RA, Russo GI, et al. Endocrine control of benign prostatic hyperplasia. Andrology 2016;4:404-11.

12. Rastrelli G, Giovannini L, Calogero AE, et al. Predictors and clinical consequences of starting androgen therapy in men with low testosterone: results from the SIAMO-NOI registry. J Endocrinol Invest 2016;39:695-708.

13. La Vignera S, Condorelli RA, Cimino L, et al. Late-onset 
hypogonadism: the advantages of treatment with human chorionic gonadotropin rather than testosterone. Aging Male 2016;19:34-9.

14. Isidori AM, Balercia G, Calogero, AE, et al. Outcomes

Cite this article as: La Vignera S, Condorelli RA, Calogero AE, Cannarella R, Mongioì LM, Duca Y, Cimino L, Giacone F, Aversa A. Symptomatic late-onset hypogonadism but normal total testosterone: the importance of testosterone annual decrease velocity. Ann Transl Med 2020;8(5):163. doi: 10.21037/ atm.2019.11.48 of androgen replacement therapy in adult male hypogonadism: recommendations from the Italian society of endocrinology. J Endocrinol Invest 2015;38:103-12. 